\title{
A NEW PROSTHESIS FOR ARTHROPLASTY OF THE HIP
}

\author{
José Valls, Buenos Aires, Argentina \\ Frofessor of Orthopaedic and Traumatic Surgery, University of Buenos tives
}

Arthroplasty of the hip has been performed since the early years of this century by many orthopaedic surgeons including Murphy (1912), Putti (1924), Mathieu (Merle D'Aubigné et al. 1951) and Campbell (1921). Many hundreds of cases of arthroplasty with or without the interposition of fat or fascia have been available for study. The results vary in the hands of different surgeons and according to the time that has elapsed since the operation; but published reports of large series observed for five years or more after operation suggest that structurally the condition of the hip is liable to deterioration. Speed and Knight (1949) describe the changes after fascial arthroplasty as follows: "After an initial period of osteoporosis, the newly reconstructed head and neck will follow one of two courses. As shown by a rather substantial portion of the cases, despite graduated exercises and protective weight-bearing, the atrophy and osteoporosis increase, with a consequent gradual absorption of the head and neck, until at least a portion of the pressure force is shared with the trochanteric surface. As shown by a second group, after a period of from three to six months,

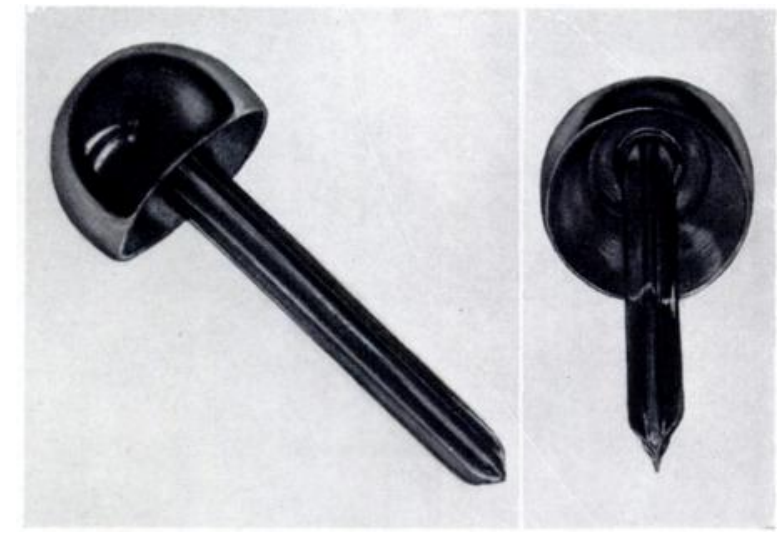

FIG. 1

The prosthesis.

the physiologic effect of weight-bearing and function is demonstrated by the reappearance of bony trabeculae in the line of condensation which forms just below the articular surface. In the latter group, the general contour and size of the head and neck may remain stationary over a period of years. With the resumption of active use over a period of time, the cortex thickens, the surface of the head becomes irregular, and progressive sclerosis associated with areas of aseptic necrosis and proliferation may be observed. Gross infarction or aseptic sequestration of a large portion of the head may occasionally take place. These pathologic changes have been observed for more than five years. Fortunately, however, the roentgenologic appearance of a joint following fascial arthroplasty does not necessarily provide an accurate index of the functional capacity of the reconstructed hip; the function of many of these joints may remain essentially unimpaired for years, despite advanced structural changes. 
"Practically all of the hips observed for a period of ten years or longer manifested considerable sclerosis and degenerative changes. Some of these were associated with a considerable decrease in function, as evidenced by pain, muscle spasm, and gradually

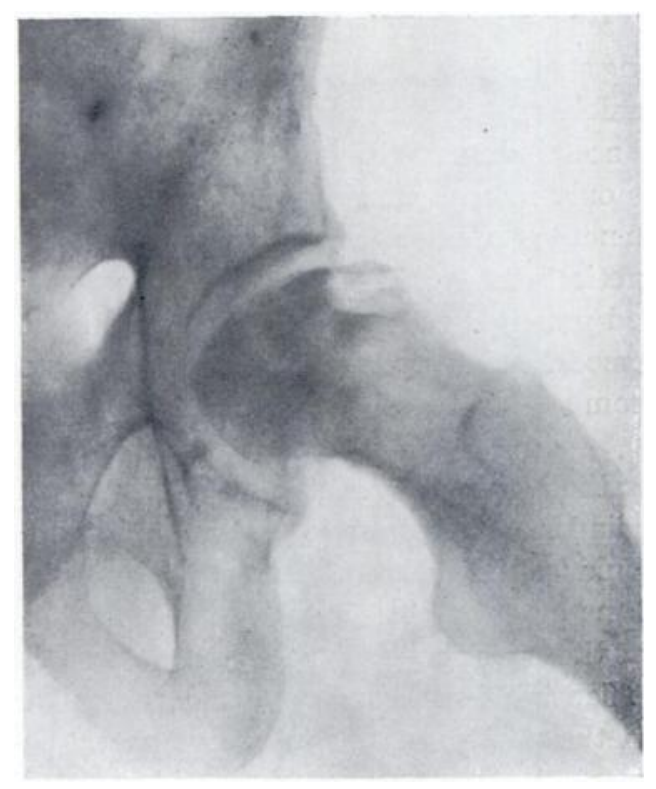

FIG. 2

Case 1-Before operation.

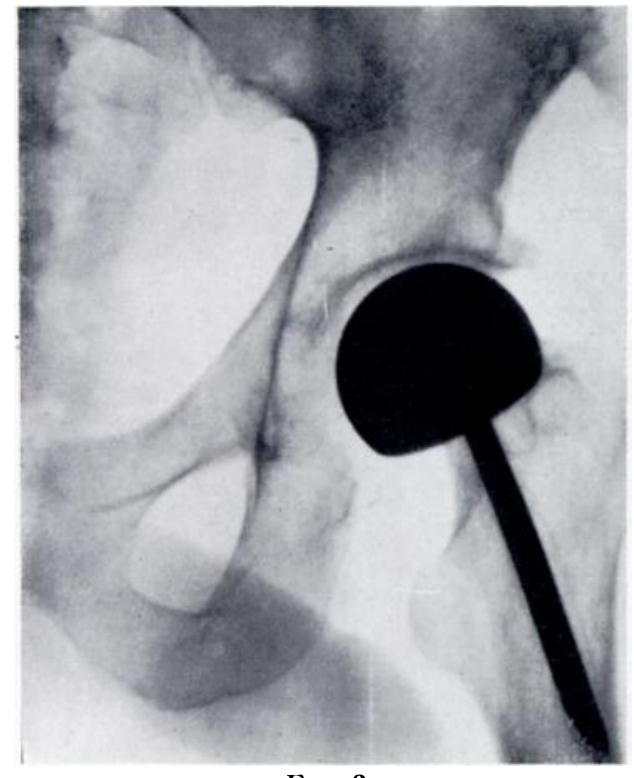

FIG. 3

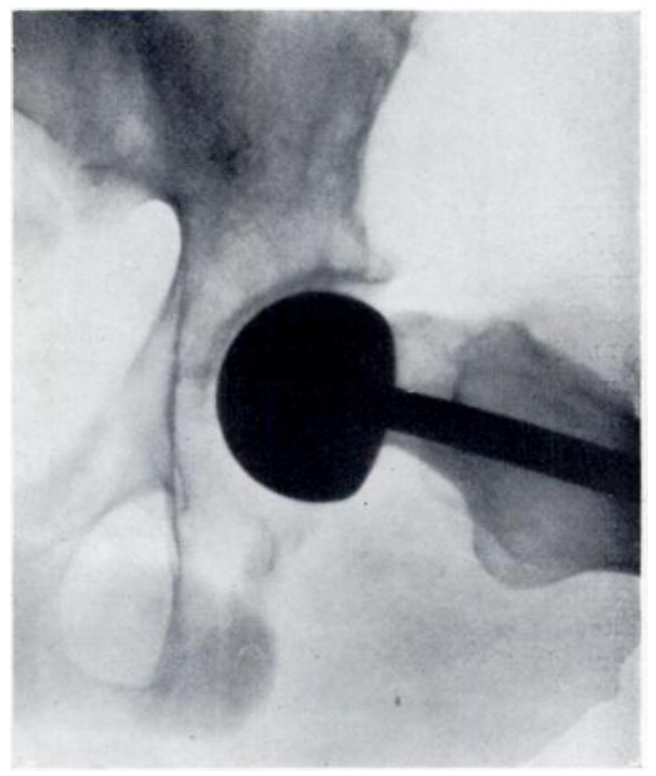

Fig. 4

Case 1 -Two years after operation. Figure 3 shows range of adduction, and Figure 4 the abduction.

restricted motion. In others, the roentgenographic changes were out of proportion to the decrease in function."

Because of these indifferent results the introduction of vitallium mould arthroplasty by Smith-Petersen $(1939,1949)$ was accepted with enthusiasm by many specialists. Experience VOL. $34 \mathrm{~B}$, NO. 2, MAY 1952 
with this method revealed that the absorption and wearing away of the head and neck of the femur is greatly reduced and that the anatomy of the joint is much more normal than it is after fascial arthroplasty.

In $1948 \mathrm{R}$. and J. Judet (1951) introduced their new technique in which the femoral head is excised and replaced by an acrylic head firmly fixed to the remaining part of the neck of the femur by a long stem. Smith-Petersen insisted that the cup must be fitted loosely, to allow the greatest possible range of movement between it and the reshaped surfaces of the femoral head and the acetabulum. With the Judet technique of resection-reconstruction, the artificial head moves only in the acetabulum. The results seem better with the Judet prosthesis, but cases have not yet been observed for long enough to make definite conclusions.

To avoid some theoretical disadvantages of the acrylic head I have designed and used in several cases a modified prosthesis. This is essentially similar to Smith-Petersen metallic cup, fixed solidly to the remodelled head and neck by stem. The prosthesis is shown in Figure 1. It may be made either from stainless steel or vitallium. The stem is fluted or flanged like a three-flanged nail.

Advantages - We consider that with the Judet acrylic head, too much resection of bone is necessary and that the cylindrical stem destroys nearly a third of the diameter of the femoral neck. Moreover, if it should be necessary to remove the prosthesis, very little bone is left for the performance of some other operation, such as an arthrodesis. Our prosthesis avoids this inconvenience. It has the same shape as the normal femoral head, but unlike the acrylic head, it is hollow, and the flanged stem destroys only a very small amount of bone of the neck.

So far we have used the new prosthesis in twelve operations; some of these patients have regained almost a normal range of movement, and most of them are free from pain. Radiographs of one patient are shown in Figures 2 to 4 . The operation was performed three years ago, and it can be seen from the radiographs that a good range of movement has been regained. The patient has no pain at all and has returned to his previous work which involves standing or walking for eight hours a day.

\section{REFERENCES}

CAMPBELl, W. C. (1921): Arthroplasty of the Knee-Report of Cases. Journal of Orthopaedic Surgery, N.S. 3, 430.

Judet, R., Judet, J., Lagrange, J., and Dunoyer (1951): Résultats des arthroplasties de la hanche avec tête acrylique. Mémoires de l'Académie de Chirurgie, 77, 352.

Merle D'Aubigné, R., Cauchoix, J., Ramadier and Postel (1951): 250 arthroplasties de la hanche avec interposition inerte. Premiers résultats. Mémoires de l'Académie de Chirurgie, 77, 199.

Murphy, J. B. (1912): Ankylosis of the Hip-Arthroplasty. Surgical Clinics of John B. Murphy, 1, 243.

Purtr, V. (1924): Arthroplastiche. Sixième Congrès de la Société Internationale de Chirurgie, Londres, 1923. Bruxelles: Imprimerie Médicale et Scientifique, p. 233.

Smith-Petersen, M. N. (1939): Arthroplasty of the Hip, a New Method. Journal of Bone and Joint Surgery, 21, 269.

Smith-Petersen, M. N. (1949): Mold Arthroplasty of the Hip. Campbell's Operative Orthopaedics. Edited by J. S. Speed and H. Smith. Second edition, Vol. II, p. 1088. London: Henry Kimpton.

SpeEd, J. S., and KNight, R. A. (1949) : Cited in Campbell's Operative Orthopaedics. Edited by J. S. Speed and H. Smith. Second edition, Vol. II, p. 1086. London: Henry Kimpton. 